\title{
DOSSIÊ
}

Sociologias, Porto Alegre, ano 17, no 39, mai/ago 2015, p. 164-196

\section{Onde no mundo estão os valores? Exemplaridade, Moralidade e Processo Social}

\section{Resumo}

Este artigo constitui um ensaio sobre valores. Trata de aportar uma resposta social e psicologicamente realista à questão de onde as pessoas descobrem valores no mundo. Pretende ser uma contribuição aos crescentes debates antropológicos sobre a moral e sugere que o tema dos valores deve ser central nesses debates. Os valores, penso eu, são aquilo que, pelo menos em parte, nos levam a desejar fazer o bem. O que as pessoas de fato farão depende não só de como equilibram os desejos concorrentes despertados por diferentes valores, mas de como equilibram esses desejos com os sentimentos de dever que distintos fatos morais também despertam. Na origem deste ensaio, está a noção de que existe alguma relação entre valores, desejos e ações morais que vale investigar. Começo discutindo a perda, por parte das ciências sociais, da fé na noção de cultura e do problema que daí advém de como falar sobre onde se encontram os valores no mundo. O que pretendo propor aqui é: se aceitarmos ser pouco provável existirem valores plenamente compartilhados, como julgavam os antropólogos, porque já não podemos supor que eles sejam parte de um fenômeno duradouro e disseminado chamado cultura - então, teremos de enfrentar uma nova questão, qual seja, a de onde existem valores no mundo. Quero sugerir que os valores existem, primeiramente, naquilo que vou chamar de exemplares ou exemplos, ou que, pelo menos, as pessoas os encontram no mundo pela primeira vez desta forma. Por fim, quero propor que os exemplos são concretizações de valores únicos em sua plenitude.

Palavras-chave: Antropologia moral. Psicologia social da moral. Cultura. Etnografia.

*Universidade de Cambridge (Reino Unido) 


\title{
Where in the world are values? \\ Exemplarity, Morality and Social Process
}

\begin{abstract}
This is an essay about values. It is concerned with providing a socially and psychologically realistic answer to the question of where people find values in the world. I mean it to be a contribution to the rapidly growing anthropological discussion of morality, suggesting that the topic of values should be central to it. It is values, I think, that at least in part account for the desire we have to do what is good. What people actually do will depend not only with how they balance the competing desires different values awaken within them, but how they balance these desires with the feelings of duty different moral facts also arouse. In the background of this essay is the notion that there is some relationship between values, desires and moral actions that is worth investigating. I begin by discussing the social scientific loss of faith in the notion of culture and the problem this raises of how to talk about where values exist in the world. What I want to propose here is that if we accept that values are not likely to be as fully shared as anthropologists once supposed because we can no longer assume they are part of an enduring shared phenomenon called culture - then we will need to face a new the question of where in the world values exist. I want to suggest that values exist in the first instance in what I am going to call exemplars or examples, or at least that people first encounter them in the world in this form. I ultimately want to suggest that examples are concretely existing realizations of single values in their fullest forms.

Keywords: Moral anthropology. Social psychology of morality. Culture. Ethnography.
\end{abstract}

•Tradução: Liana Fernandes (UFRGS) 
Sociologias, Porto Alegre, ano 17, no 39, mai/ago 2015, p. 164-196

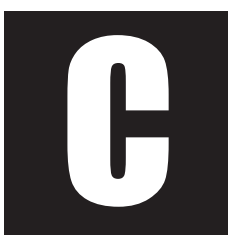

omo logo se tornará evidente, este é um ensaio sobre valores. Seu propósito é oferecer uma resposta social e psicologicamente realista à questão de onde as pessoas encontram valores no mundo. Também pretendo que seja uma contribuição à crescente discussão acerca da moral. Com algumas exceções dignas de menção, os antropólogos só começaram a discutir sistematicamente a ética e a moralidade há cerca de uma década, mas rapidamente recuperaram o tempo perdido e estão atualmente produzindo um grande número de estudos na área' Em termos gerais, pretendo sugerir que o tema dos valores deveria ter papel central nessas discussões em curso (ROBBINS, 2012b). Durante a produção deste ensaio, contudo, descobri que, ao lidar com o problema de onde as pessoas encontram valores, tive pouco espaço para discutir explicitamente a ligação entre valores e moralidade. Em vista disso, acho interessante mencionar, já de início, que sigo Durkheim (1974) ao definir fatos morais como aqueles que despertam nas pessoas um senso tanto de dever quanto de desejo. São os valores que, penso eu, representam pelo menos em certa medida a parte do desejo nessa mistura - o desejo que temos de fazer o bem. O que as pessoas efetivamente fazem irá depender não só de como elas equilibram os desejos concorrentes nelas despertados por diferentes valores, mas como elas equilibram esses desejos com os sentimentos de obrigação que diferentes fatos morais também evocam. Por esse motivo, a relação entre o que as pessoas valorizam e o que elas fazem com o propósito de cumprir ações morais é muito complexa. Assim, como pano de fundo deste ensaio, está a noção da existência de alguma relação entre valores, desejos e ações morais que vale investigar.

\footnotetext{
${ }_{1}^{1}$ Para uma análise recente abrangente, ver Laidlaw (2013); para uma revisão parcial de algumas questões importantes na literatura emergente, ver Robbins (2012a).
} 
Sociologias, Porto Alegre, ano 17, no 39, mai/ago 2015, p. 164-196

Apresento aqui um resumo muito sucinto e rudimentar da psicologia social da moralidade, a qual fundamenta este artigo. É uma psicologia social da moralidade que confere lugar de destaque aos valores e, para ser plenamente realista tanto da perspectiva psicológica quanto da social, deve incluir uma narrativa psicológica e socialmente realista de como as pessoas vivenciam valores. Com esse propósito, desenvolvo o presente ensaio. Há muitas décadas, antropólogos e muitos sociólogos acreditavam ter uma resposta segura para a questão de onde existem valores no mundo e onde as pessoas os encontram. Essa resposta afirmava que seres humanos são animais culturais, valores são parte da cultura, e as pessoas recebem seus valores através de sua socialização dentro de culturas. Mas uma recente perda de confiança no conceito de cultura deixou essa resposta menos convincente do que foi um dia. Começo, portanto, discutindo essa perda de confiança das ciências sociais na noção de cultura e o problema, suscitado pela mesma, de como falar sobre onde os valores existem no mundo. Tendo começado por aí, a partir desse ponto não falarei muito sobre moralidade, mas espero ter dito o suficiente para indicar que ela está no horizonte para o qual se encaminharão enfim os argumentos que aqui apresento.

$$
* * *
$$

Se observarmos a antropologia hoje, será difícil não perceber que estamos em meio ao que se pode chamar de um momento fortemente anticultural. Se o estudo da cultura consiste em observar e explicar padrões repetitivos de comportamento e os complexos recorrentes de significado ou entendimento que os moldam, então uma antropologia totalmente focada na emergência, novidade e permanente mutação de grupos ou redes de pessoas, coisas e ideias pode rejeitar essa noção. De forma semelhante, se sustentarmos a ideia de que o mundo é recriado e renovado a cada momento, a cultura é lenta demais, pesada demais, arrastada demais para 
Sociologias, Porto Alegre, ano 17, no 39, mai/ago 2015, p. 164-196

ser analiticamente útil. Melhor é abordar nosso objeto de estudo através do desenvolvimento de modelos de processo e transformação, se quisermos explicar um mundo que supomos ser muito mais fluido do que o mundo da cultura jamais foi, ou se pretendeu que fosse.

Entendo ser essa uma explanação muito apressada do que é, no máximo, apenas uma parte do Zeitgeist antropológico contemporâneo. Para complementá-la, tentarei mais tarde descrever um pouco mais detalhadamente um dos caminhos que a antropologia seguiu até chegar a esse ponto anticultural. Mas quero, desde já e brevemente, chamar atenção a esse aspecto do Zeitgeist, pois o fato de essa ênfase anticultural estar ganhando impulso atualmente - parece estar atraindo muitas das melhores forças teóricas da antropologia nos dias de hoje - proporciona um importante arcabouço para o argumento que quero desenvolver aqui. Com efeito, esse argumento emerge do fato de eu reconhecer que, hoje, a cultura é um mote cada vez mais difícil de defender, embora me encontre, ainda, relativamente satisfeito com o conceito de cultura - especialmente a versão em que a valorização antropológica cultural de seus aspectos mais idealistas é complementada com ferramentas proporcionadas pela antropologia linguística, as quais nos permitem focar em como ela se realiza e se reproduz nas interações. Uma vez inclinado nessa direção contrária, ou até antiquada, devo questionar-me: o que alguém com essas inclinações poderia dizer produtivamente agora?

Sou movido por dois impulsos diferentes no que concerne a como responder essa pergunta. Uma forma seria lançar-me na defesa total do conceito de cultura, tratando, no transcurso, de pôr em questão a importância, senão a existência dos aspectos emergentes e fluidos do mundo, destacando, entre outras coisas, os aspectos solidamente estruturados das vidas que, de fato, habitualmente vivemos. Em meus momentos mais tranquilos, imagino que montar uma defesa em grande escala do concei- 
Sociologias, Porto Alegre, ano 17, no 39, mai/ago 2015, p. 164-196

to de cultura com esses contornos seria uma grande empreitada, a qual possivelmente tomaria tanto tempo que, quando eu estivesse pronto a expô-la, o momento oportuno de fazê-lo já teria passado. Além disso, pode ser cedo demais, de qualquer modo, para investir em tal defesa. Melhor, talvez, seria aguardar até a antropologia anticultural estar suficientemente madura para que seus argumentos mais fortes tenham emergido e possam ser plenamente identificados e diretamente enfrentados. E, finalmente, tenho uma sensação inquietante de que, talvez, seja melhor não me apressar na defesa da noção de cultura contra esses ataques, mas sim começar perguntando que coisas novas se podem aprender sobre a cultura, explorando algumas das questões que eles levantam.

Tendo presentes essas preocupações, e particularmente intrigado com a possibilidade de aprender algo novo sobre a cultura dando às recentes críticas anticulturais a atenção que merecem, meu segundo e mais modesto impulso venceu. Esse aponta para o intento de questionar de que modo - supondo que a cultura não seja uma força tão poderosa na configuração da vida social quanto os antropólogos costumavam pensar poder-se-ia explicar de novas maneiras a existência de algumas das principais coisas culturais cuja identificação e análise costumávamos apoiar no conceito de cultura. Há alguns anos, escrevi um artigo nesses termos, perguntando como podemos ainda pensar sobre o ritual em termos durkheimianos, da perspectiva de marcos teóricos que afirmam não existir essa coisa chamada sociedade. Hoje, quero tomar outro objeto clássico dos estudos culturais - os valores - e interrogar se poderíamos descobrir onde eles existem na vida em sociedade. Essa se torna uma questão premente, se deixarmos de lado, ao menos para fins argumentativos, a afirmação de que eles existem no âmbito de um fenômeno duradouro e regularmente reproduzido chamado cultura. 
Sociologias, Porto Alegre, ano 17, no 39, mai/ago 2015, p. 164-196

Na realidade, a questão de onde se podem situar os valores não é recente - surgiu muito antes de nossos atuais debates anticulturais, emergindo, de fato, quase simultaneamente a algumas das ideias que vieram a contribuir para formar a hoje contestada noção moderna de cultura. Correndo o risco de demorar-me um pouco mais num nível relativamente abstrato de argumentação, quero rever um pouco da história dessa questão de onde existem os valores, como forma de me encaminhar para meu argumento principal.

É importante reconhecer, já de início, que o uso do termo valor com o qual estamos habituados não é muito antigo. Ele surge inicialmente em meados do Século XIX, quando filósofos o tomam dos economistas políticos (SCHNÄDELBACH, 1984, p. 161). Desde então, discussões sobre a natureza dos valores desempenham um papel importante, especialmente na filosofia alemã, e também nas ciências sociais que começam a surgir, até a década de 1920, em seguida desaparecendo de grande parte do cenário das ciências sociais que não seja o de seu berço na economia. Para nossos objetivos, é importante observar que os valores tornaram-se uma preocupação no final do Século XIX no momento em que a perspectiva científico-materialista se arraigou como a ideia moderna dominante sobre a natureza da existência. Nessa visão de mundo, tudo o que existe é matéria, e a matéria é em si desprovida de significado ou propósito. O que existe não é bom ou ruim, belo ou feio, verdadeiro ou falso (o clássico triunvirato das dimensões de valor) - simplesmente é. Nessa visão de mundo, como todos sabemos, não há meio intelectualmente legítimo de passar do ser para o dever ser - do fato para o valor. Essa forma de interpretar as coisas deixou aos filósofos uma questão crucial - de que modo existem os valores? Se o bem, ou o belo, ou o verdadeiro, por definição não podem existir, uma vez que o que existe é matéria e a matéria não tem significado ou valor em si, então qual é o seu modo de existência no mundo? Essa é a questão que move a filosofia do valor. 
Como cientistas sociais, estamos mais familiarizados com esse conjunto de problemáticas a partir de Weber, que foi influenciado por algumas das discussões alemãs sobre a natureza do valor referidas anteriormente. Ele legou às ciências sociais a concepção de enorme influência, emergente dessa problemática filosófica (e fundamentalmente do protestantismo, mas essa é outra história - ver ALBROW, 1990; SCHELER, 1973, p. 67), de que o mundo (incluindo a existência humana) considerado em termos materiais é um fluxo caótico que só adquire sentido quando os seres humanos impõem seus valores ao mesmo. Sob esse ponto de vista, os valores existem no pensamento humano e se manifestam na ação humana, e essa ação, por sua vez, ordena o mundo segundo modos compreensíveis para os seres humanos. A afirmação de que valores são ideias que motivam ações é, portanto, uma resposta à questão sobre o modo de existência dos valores. Mas, enquanto resposta à questão de como os valores existem, uma que busque explicar por que os seres humanos não vivem em mundos caóticos e sem sentido, ela deixa pendente um problema. Este é: por que razão cada ser humano não impõe ao mundo seu próprio conjunto singular de valores, fazendo com que a vida em sociedade tome a forma de uma cacofonia de projetos opostos, cada um baseado em estruturas completamente singulares de significação do caos da existência material. Isso só levaria a outra situação caótica sem sentido - uma guerra humana de todos contra todos, sobre quais sistemas de significação irão prevalecer. A noção antropológica de cultura é uma solução para esse segundo problema de como os valores, sendo ideias que motivam a ação, podem criar um mundo ordenado, pois sugere que os valores são compartilhados entre os membros de uma sociedade. Indivíduos que compartilham valores, nesse modelo, impõem juntos, de forma similar, ordem ao caos da existência, possibilitando assim, viver juntos de forma relativamente ordenada. 
Diversas versões dessa solução cultural para o problema de como os valores existem no mundo e o ordenam de forma a dar-lhe sentido serviram à antropologia por grande parte do Século XX (o que pode ser a razão pela qual a questão dos valores não tem sido recentemente um interesse central na área). Mas nos últimos 25 anos, aproximadamente, essa solução cultural foi abandonada por muitas vertentes. Para um grande número de antropólogos contemporâneos, a causa mais provável desse abandono foi a virada pós-moderna - uma expressão que, agora percebo, só pode soar um tanto antiquada, quase nostálgica, mas que é útil para dar nome a um movimento intelectual cujos efeitos ainda marcam o cenário intelectual atual, pelo menos na antropologia.

Foi a virada pós-moderna que fez com que as noções de cultura compartilhada parecessem deterministas demais, desrespeitosas demais com a realidade do caos e com a verdadeira individualidade das pessoas - muitos antropólogos chegaram a acreditar que cada uma delas tem, sim, sua própria posição e perspectiva sobre o mundo. De uma perspectiva mais distanciada, que apenas começa a entrar em foco, pode mesmo ficar comprovado que esse abandono das noções de cultura compartilhada resultou, na realidade, de outra grande virada da perspectiva científica e de sua negação de significação para o que existe, uma virada que a crítica pós-moderna do sentido e da estrutura involuntariamente ajudou a acontecer e que fica evidente, por exemplo, na ascendência contemporânea de modelos cientificistas nas ciências sociais e humanas, inclusive em muitos dos posicionamentos teóricos anticulturais com os quais comecei. Mas, independentemente dos motivos para nossa atual situação, é certamente verdade que hoje em dia muitos antropólogos não se inclinam a ver a ideia de cultura compartilhada como uma boa resposta à questão de como os valores existem no mundo, e estão, em termos anticulturais, mais interessados em documentar os aspectos caóticos ou emergentes do mundo do que 
aqueles ordenados e previsíveis. Meu argumento aqui é que, se aceitarmos ser esse o caso - ser pouco provável que os valores sejam tão completamente compartilhados quanto os antropólogos costumavam supor, pois não podemos mais assumi-los como parte de um fenômeno duradouro chamado de cultura - então precisamos encarar novamente a questão de onde no mundo existem os valores. Ao fornecer uma nova resposta a essa pergunta, quero sugerir que os valores existem, em primeira instância, no que chamarei de exemplares ou de exemplos, ou que, pelo menos, as pessoas os encontram no mundo inicialmente nessa forma.

O que é, então, um exemplo? Fundamentalmente, sugiro que os exemplos são realizações concretamente existentes de valores únicos em sua forma mais plena. Tendo oferecido essa definição, compreendo que será preciso certo trabalho argumentativo para torná-la convincente, ou até mesmo compreensível; portanto, permitam-me começar um pouco mais para trás na minha linha de raciocínio. Um bom lugar para nos voltarmos no princípio é a obra do filósofo italiano Alessandro Ferrara (2008). Em um livro intitulado "The Force of the Example", Ferrara defende que reconhecemos facilmente dois tipos de forças no mundo. Há a força do que existe, ou o que ele chama de força das coisas (1). E há, também, ao menos para os seres humanos, a força do que deveria ser - a força das ideias (p. 2, ênfase removida). Essas duas forças, admite Ferrara, alinham-se com a dicotomia moderna entre fato e valor, ou o real e o ideal (ix). Mas, como vimos, isso nos deixa com o problema da natureza da existência de valores - pois, se o ideal ou os valores são definidos precisamente por não existirem como coisas materiais no mundo, então onde eles existem? Se eles só existem na mente das pessoas, por que o mundo não é uma confusão caótica de indivíduos realizando projetos completamente desvinculados uns dos outros? Embora as questões de Ferrara estejam próximas dessas, ele não as propõe exatamente dessa maneira. Mas, 
ainda assim, ele nos oferece alguma ajuda para respondê-las, quando propõe que os dois lados da dicotomia entre o que é e o que deveria ser precisam ser complementados por um termo intermediário - a força do que é como deveria ser, ou a força do exemplo (p.2-3, ênfase removida). [A] força do exemplo, ele segue afirmando, é a força daquilo que exerce um apelo sobre nós [...] em virtude da congruência singular e excepcional que o que é exemplar realiza e exibe entre a ordem de sua própria realidade e a ordem da normatividade a que responde (3). Para pôr em termos que usarei a partir de agora, um exemplo é uma realização de um valor no mundo, e pede nossa atenção precisamente por essa razão.

Quando afirmo que um exemplo é a realização de um valor no mundo, refiro-me a isso em um sentido um tanto especial. Em alguns aspectos, toda ação humana realiza, ou pelo menos busca realizar, algo que $\mathrm{o}$ ator define como tendo valor no contexto em que ele a executa. Essa é uma visão muito comum da motivação humana e não pretendo de contrariá-la aqui. Considerando-se essa visão, é também correto dizer que toda ação, como realização de um valor no mundo, é exemplar? Se isso for verdade, então nada do que estou dizendo sobre exemplos seria útil.

Para contornar esse problema, quero esboçar muito rapidamente uma explicação de como os valores operam na ação, sugerindo que a maioria das ações, mesmo sendo motivadas por valores, não realizam plenamente qualquer um deles e, portanto, não são exemplares. Permitam-me começar afirmando que em qualquer meio social há muitos valores em jogo. Ao invés de defendê-la, aqui, considerarei essa afirmação da pluralidade dos valores em qualquer sociedade como um dado (como já fiz em outros escritos: ROBBINS, 2013), e espero que o leitor a considere suficientemente plausível, com base no que sabe a respeito da vida em sociedade, permitindo que ela se sustente para os fins da presente argumentação. Então, dado que em toda sociedade existe uma quantidade 
de valores, podemos seguir observando que alguns desses valores funcionam em conjunto, de tal forma que realizar um valor ajuda a realizar outro considerado ainda mais alto, e assim por diante, configurando o que Nancy Munn (1986) denomina cadeias de transformação de valor. Por exemplo, na Ilha de Gawa, Papua-Nova Guiné - uma sociedade em que as pessoas participam do sistema de intercâmbio Kula, que ficou conhecido através de Malinowski - se você é um homem, deve plantar hortas de taro e inhame para dar à família do marido de uma de suas parentes muIheres, para que essa família possa depois Ihe dar um bem de valor Kula e uma canoa, para que você possa futuramente permutar em circuitos Kula para aumentar seu raio de controle espaço-temporal e assim reforçar sua fama (MUNN, 1986, p. 123-129). A cada passo você age em termos de valor, embora o propósito fundamental de toda cadeia só seja dado pela transformação final que aumenta sua fama, um resultado que realiza o valor geral da cadeia. Na maior parte do tempo, você realiza apenas valores de grau mais baixo em ações que terão tido uma significância limitada se a cadeia nunca for completada.

Em comparação a conjuntos de valores que se interligam em cadeias de transformação de valor, há também valores que não funcionam em conjunto dessa forma, mas, em vez disso conflitam, de maneira que realizar um impossibilita realizar o outro. Dentre alguns grupos da Papua-Nova Guiné, por exemplo, uma dádiva concedida à família do cônjuge para obter acesso a terras é uma dádiva não dada aos membros de sua tribo a fim de garantir apoio em disputas. Ao serem confrontadas com uma escolha exclusiva entre valores desse tipo, as pessoas geralmente se esquivam, realizando ambos parcialmente, mas nenhum dos dois plenamente.

Nesses dois tipos de relação de valor - a de cadeias de valores e a de conflitos de valores - os mesmos são com frequência, talvez usualmente, negociados na ação. A maioria das ações ou não realiza um valor de 
grande importância, mas apenas um que é um elo em uma cadeia orientada para a realização de outro valor, ou é impulsionada por uma mistura de considerações sobre valores parciais. É por isso que nem toda ação é exemplar, mesmo que toda ação seja motivada por valores².

Tendo como base esse argumento de que a maioria das ações não realiza os valores mais importantes para os indivíduos, ou apenas os realiza de forma limitada, quero sugerir que algumas ações se destacam por cumprir o oposto. Há algumas ações ou produtos de ações que realizam valores importantes em suas formas mais plenas, ou ao menos chegam perto disso. São essas ações e seus produtos que se tornam exemplares e que têm, como coloca Ferrara, uma "força" que pede um tipo especial de atenção ou demanda valorização por parte das pessoas. Os exemplos, por essa razão, são formas sociais que realizam um valor nessa plenitude. É dessa maneira, incorporados nos exemplos, que os valores existem de modo mais vigoroso ou tangível na vida em sociedade.

Até o momento, discuti a ligação entre exemplos e valores em relação a ações exemplares tomadas como um fenômeno global. Mas para que essa argumentação seja realista, é preciso reconhecer que o aparecimento dos exemplos não é aleatório na vida em sociedade. Eles não ocorrem, ou pelo menos as pessoas não tendem a encontrá-los, em qualquer lugar, nem são executados por qualquer um. Em qualquer sociedade, há pessoas específicas - vivas ou históricas - reconhecidas por terem cultivado a capacidade de realizar um ou outro valor, e que, portanto, são exemplares em relação a ele. Então, uma das maneiras em que as pessoas

\footnotetext{
${ }^{2}$ Também gostaria de observar rapidamente que o fato de haver sempre múltiplos valores em jogo, combinado ao fato de a maioria das ações não realizar plenamente os valores considerados mais importantes pelas pessoas, é o que confere à vida em sociedade o tipo de complexidade que leva muitos antropólogos a abandonar noções de ordem e cultura. Mas essa complexidade não é prova da ausência de valores, e sim deriva de sua existência.
} 
encontram exemplos na vida em sociedade é na forma de pessoas exemplares. Também quero argumentar que realizações de valor consumadas podem existir em determinados tipos de instituições. Penso que, muitas vezes, tais instituições de valor-consumado tomam a forma de rituais. Exemplificações de valor provavelmente também encontrem existência mais ou menos regular em outros aspectos da vida em sociedade, por exemplo, nos mitos (SCHELER, 1987, p. 146). Mas, para os objetivos presentes, manterei o foco em pessoas exemplares e rituais, a fim de tentar delinear em termos etnográficos onde nós, tanto como analistas quanto como as pessoas que estudamos, encontramos os valores existentes na vida em sociedade.

Começarei com as pessoas exemplares. Ao se pensar sobre essas pessoas, pode-se recorrer à obra de Max Scheler, um dos mais importantes filósofos e sociólogos do valor do final do século XIX - início do século $X X$. Em seu ensaio "Exemplars of Person and Leaders", Scheler define exemplares, de modo similar ao que usamos aqui, como a junção da ideia de um valor com uma pessoa (p. 134), ou, como ele também expressa seu ponto de vista, como o molde de um valor formado pela condição de pessoa - molde, aqui, usado no sentido de uma fôrma na qual a condição de pessoa deve se encaixar para se realizar como tendo valor ( $p$. 139, ênfase no original). Consideramos nossos exemplares, Scheler ainda explica, como algo bom, perfeito, e algo que deve ser (p. 133). Ademais, nos relacionamos com os exemplares especialmente com base em nossa "fé" nos mesmos. Essa não é uma fé religiosa, Scheler logo complementa, mas uma fé no sentido de um amor fundamentado, evidente e verdadeiro, e da plena percepção do conhecimento do exemplar e de seu valor ( $p$. 144). Essa referência de Scheler ao amor não é gratuita, uma vez que ele reconhecidamente desenvolveu uma fenomenologia da percepção do valor na qual as emoções, o amor e o ódio sendo proeminentes dentre elas, 
são os "órgãos" que percebem valores no mundo. Mas chamo atenção à afirmação de Scheler de que amamos nossos exemplares, não para abrir uma discussão sobre sua elaborada fundamentação teórica, mas sim para vinculá-la à afirmação de Ferrara de que o exemplar exerce uma força, que ele nos atrai e demanda uma resposta. Tentarei convencê-los de que isso tem sustentação etnográfica, em breve. Mas, para terminar de expor as ideias de Scheler, permitam-me apenas acrescentar que é com base nas conexões forjadas por esse amor e nas motivações trazidas por ele que as pessoas irão se esforçar para perceber valores em si mesmas. [É] como se, coloca Scheler, os seres humanos motivassem a si mesmos por tais linhas exemplares inter-humanas (p. 143, ênfase no original). É por isso que, para Scheler: O que tem um efeito formador e cala fundo em nossas almas não é uma regra moral universal abstrata, mas sempre, e unicamente, um entendimento claro e intuitivo da exemplaridade da pessoa (p. 134).

A abordagem para a análise da existência e força dos valores na vida em sociedade, que construí com ajuda de Scheler, incentiva-nos a examinar etnograficamente quais indivíduos as pessoas das sociedades que estudamos tratam como exemplares e que valores eles realizam. No lugar onde fiz trabalho de campo, entre os Urapmins da Papua-Nova Guiné, o molde das personagens exemplares, em geral, não é difícil de identificar; há algumas pessoas das quais os Urapmins falam muito mais do que de outras, sobre quem relatam ter sonhos com grande frequência, e por quem claramente se orientam para pensar nas possibilidades que a vida Ihes oferece. Como os Urapmins, via de regra, não costumam bisbilhotar, o fato de eles regularmente discutirem os feitos desse grupo relativamente pequeno de pessoas é uma forte evidência do quão importantes elas são para eles. Antes de analisar em mais detalhes a qualidade exemplar dessas personagens, vale apresentar brevemente a sociedade Urapmin e os valores mais gerais que a conformam. 


\section{Encontrando valores entre os Urapmins de Papua-Nova Guiné}

A comunidade Urapmin tem aproximadamente 390 pessoas e está localizada na província de Saduan em Papua-Nova Guiné. Já descrevi em outros trabalhos o principal valor tradicional que orienta o povo Urapmin: o relacionalismo - um valor que define a criação e manutenção de relações como a coisa mais importante que as pessoas fazem (ROBBINS, 2004). Embora se possa argumentar que o relacionalismo é comum por toda Melanésia - como se evidencia, por exemplo, na forte tendência entre os povos da região de descobrirem nas trocas de formação e manutenção de relações a atividade social mais compensadora - sua proeminência é talvez ainda mais destacada em sociedades cognáticas como a Urapmin, uma forma de organização social que torna as pessoas constantemente cientes da necessidade de criar relações de residência, parentesco, trabalho, entre outras, nenhuma das quais constituída por regras estruturais que pudessem fazê-las aparecer espontaneamente. Domicílios, aldeias, grupos de trabalho, times de futebol, igrejas e todas as outras congregações relacionais mudam de composição regularmente entre os Urapmins, e todos reconhecem que é preciso um trabalho relacional para uni-los e permitir-lhes seguir em frente. Por esse motivo, os Urapmins passam a maior parte do tempo trabalhando para construir relações.

Logo abaixo do relacionalismo na hierarquia tradicional de valor dos Urapmins estão dois valores que podem, quando realizados de determinadas maneiras, sustentar os esforços relacionais das pessoas. Esses são valores a que os Urapmins se referem como o da "intencionalidade" e o da "legalidade". A intenção (san) de alguém é a parte desejosa da pessoa, e aquela que a "empurra" para tentar atrair outras para relacionamentos e mantê-las orientadas para esses relacionamentos. É a intencionalidade do pai, por exemplo, que o leva a convencer seu filho e a nova esposa deste, 
a viverem com ele, ao invés de viverem com a família dela, e então segue convencendo o casal a cuidarem do cultivo com sua família a maior parte dos dias, em vez de fazê-lo com a família da esposa. Diferente dessa intencionalidade, que procura criar novas relações ou forçar a manutenção daquelas existentes contra as demandas de outras concorrentes, a legalidade consiste em honrar o domínio que cada relacionamento existente tem sobre a energia de cada um; um domínio que cada relacionamento expressa por sua demanda de que as expectativas legítimas que esse estabelece - mais frequentemente expectativas de reciprocidade e investimento equivalente de atenção - sejam atendidas antes que qualquer outra relação receba atenção ou que qualquer outra nova seja estabelecida.

Para cumprir plenamente o valor do relacionalismo, as pessoas precisam equilibrar a realização dos valores da intencionalidade e da legalidade. Se desenvolvido plenamente, o valor da intencionalidade cria constantemente novos relacionamentos, deixando que outros mais antigos se dissolvam quando a negligência e a disputa cobram seu preço. A legalidade, por sua vez, em sua expressão, apenas atende as demandas das relações existentes e não produz nada novo - um resultado igualmente insustentável em um mundo cognático no qual nenhuma relação pode ser pressuposta e nenhuma necessariamente perdurará, portanto todas devem ser intencionalmente formadas em primeiro lugar. Uma vez que um excesso tanto de intencionalidade quanto de legalidade é fundamentalmente contraprodutivo em relação ao valor supremo do relacionalismo, a dificuldade para os Urapmins é aprender a moderara plena expressão de qualquer um desses valores subordinados, equilibrando o exercício da vontade de criar novas relações e um comprometimento com a legalidade ao mantê-las.

O que apresentei resumidamente é um esboço básico dos três principais valores tradicionalmente reconhecidos pelos Urapmins. Também 
Sociologias, Porto Alegre, ano 17, no 39, mai/ago 2015, p. 164-196

apresentei a hierarquia que os sustenta, de tal forma que a intencionalidade e a legalidade, embora valorizadas independentemente em certo grau, estão fundamentalmente subordinadas ao relacionalismo e são em geral apenas parcialmente realizadas durante a vida em sociedade. Mas a argumentação acerca do modo de existência dos valores que esse ensaio traça sugere que, para passarem a reconhecer intencionalidade e legalidade como valores, as pessoas precisam encontrar esses valores em sua forma plenamente desenvolvida, incorporados em exemplos em seu meio social. Pessoas que exemplificam esses valores nesse sentido, pretendo sugerir, são algumas das quais os Urapmins falam e com as quais sonham o tempo todo.

Veja Semis, por exemplo. Semis é um homem por quem os Urapmins sentem uma grande afeição. Ele é quase sempre um modelo de legalidade. Em 1977, os Urapmins se converteram, sem a ajuda de missionários, a uma versão vigorosa do cristianismo carismático que lhes chegou através de um movimento de renascimento que varreu Papua-Nova Guiné. Não posso contar aqui a história de como os Urapmins se tornaram, no seu próprio entendimento, uma comunidade inteiramente cristã na época. Mas, para compreender como Semis vive sua vida e o laço afetivo que muitos têm com ele como um exemplo, vale informar que ele foi uma das figuras que encabeçou o renascimento- corajosamente ajudando a executar a difícil e perigosa tarefa de descartar os poderosos restos ancestrais, que eram centrais para a religião tradicional Urapmin. Desde o renascimento, ele serviu por muitos anos como um dos principais pastores da comunidade.

O cristianismo Urapmin pregado por Semis, o qual sua congregação procura praticar, promove o comportamento pela legalidade enquanto condena completamente demonstrações de intencionalidade, e Semis chega mais perto do que a maioria das pessoas de viver segundo seus 
Sociologias, Porto Alegre, ano 17, no 39, mai/ago 2015, p. 164-196

mandamentos. Ele exibe seu caráter de legalidade de várias maneiras. Ele não tenta, por exemplo, convencer os outros a atender a suas necessidades relacionais. Como resultado, ele permaneceu viúvo por muitos anos, criando sua única filha até a juventude e formando com ela a menor, e menos complexa em termos relacionais, unidade familiar que se poderia imaginar em Urapmin, onde é preciso no mínimo um homem e uma mulher para executar o trabalho necessário para sustentar uma família. Semis também se esforça para controlar sentimentos de raiva que "surgem" quando suas expectativas relacionais são violadas. Isso significa que às vezes algumas pessoas se aproveitam dele em relações de troca, como quando, depois de algum tempo, ele aceitou sem qualquer tentativa de reparação, que o arco presenteado para estabelecer uma amizade de permuta com um visitante importante em sua casa nunca fosse retribuído, apesar das muitas visitas que fez à casa do presenteado na tentativa de induzir uma retribuição apropriada. Seu sucesso em manter sua raiva controlada lhe deu a reputação de alguém com um coração "tranquilo", o que se acredita ser a principal causa de sua conduta de legalidade.

Há outras pessoas na comunidade Urapmin tão comprometidas com a legalidade quanto Semis, mas a maioria está muito próxima do papel que Urapmin chama de "homens ineptos". Os homens ineptos são aqueles tão carentes de vontade que praticamente não têm relacionamentos. Os Urapmin têm pena de pessoas desse tipo, ao invés de condená-las, mas ao mesmo tempo não as tomam como exemplos. Pobres de recursos materiais, para os quais são necessárias relações para produzir em Urapmin, se os homens ineptos não violam a lei, dificilmente a cumprem também. Para realizar plenamente a legalidade, é preciso ter relações e também atender as demandas de tratamento recíproco que elas colocam, mesmo quando não há esforço para expandir o próprio território relacional. Semis consegue seguir legalmente suas obrigações relacionais sem 
Sociologias, Porto Alegre, ano 17, no 39, mai/ago 2015, p. 164-196

qualquer necessidade de expansão intencional das mesmas, em virtude do seu papel como pastor - uma posição que as pessoas apoiam, por vezes the dando produtos de suas hortas e ajudando-o a fazer e administrar a sua própria. Isso é feito mais ou menos espontaneamente (embora ele frequentemente desejasse que fizessem mais), e portanto ele não precisa convencer os outros para obter os recursos de que precisa para se relacionar legalmente com eles. Isso faz dele um paradigma de uma legalidade vivida solidamente - um tipo de legalidade plenamente realizada que não leva a uma marginalização social. Praticamente nenhuma outra pessoa Urapmin pode viver assim, pois elas geralmente precisam equilibrar sua realização do valor de legalidade colocando suas intenções em jogo. Mas várias admiram muito Semis. Elas o procuram em busca de conselhos, falam carinhosamente dele em sua ausência, e com bastante frequência têm sonhos em que veem Jesus levando-o para o céu.

Não foi difícil, durante o trabalho de campo, concluir que a população tomava Semis como um exemplo. Tantos deixaram clara sua afeição por ele em nossas conversas que seu status ficou óbvio para mim quase desde o início. As coisas foram diferentes com o principal exemplo de intencionalidade na comunidade. Kinimnok, um homem de 50 anos, é falante, dominador, vigoroso e extravagante de todas as formas, e ele é claramente o adulto Urapmin mais ostensivamente intencional. Pode-se observar a forma da intencionalidade plenamente realizada observando praticamente qualquer área do comportamento e personalidade de Kinimnok. Ele é, por exemplo, um caçador quase obsessivo. A caça é uma atividade prestigiosa para homens Urapmin, e o sucesso na caça lhes proporciona recursos alimentares de prestígio para dar presentes de alto nível, intencionalmente expansivos, para criar relações. Mas também se reconhece que a atividade não substitui o trabalho responsável de cultivo, no que diz respeito a alimentar uma família e cumprir as demandas legais 
Sociologias, Porto Alegre, ano 17, no 39, mai/ago 2015, p. 164-196

de uma rede relacional normal. Um bom homem dedicará um pouco de energia à caça, dizem os Urapmin, mas apenas como um complemento ao seu trabalho mais sério e mais constante de cultivo.

A ideia de que os homens não devem se envolver exageradamente com a caça, apesar de suas eventualmente ótimas recompensas, é expressa em mitos e lendas populares, nos quais homens obcecados com a caça se saem mal no fim, em comparação a seus parentes mais focados no cultivo. Isso também está complexamente embutido na crença da população na existência de uma entidade conhecida como NukWanang, ou a MuIher Marsupial. A Mulher Marsupial é um espírito guardião dos marsupiais que os humanos caçam e comem. Às vezes ela se envolve com homens que caçam frequentemente. Quando uma Mulher Marsupial começa a ter relações sexuais com um desses homens, e depois de algum tempo se casa com ele, ela também lhe dá sonhos the dizendo onde encontrar caças. Esse homem se torna então um caçador espetacularmente eficaz. Mas há um lado ruim nesse arranjo, pois, em algum momento, a Mulher Marsupial fica com ciúmes da esposa humana do caçador e começa a achar que está abrindo mão de muitos de seus marsupiais protegidos em troca de muito pouco do caçador. Nesse momento, ela começa a lhe mandar avisos de sua insatisfação, fazendo com que ele sofra acidentes durante as caçadas e por fim o matando.

Conheci muitos homens Urapmin que, começando a desenvolver uma vocação como bons caçadores, começavam a suspeitar que a MuIher Marsupial estava tentando seduzi-los ao Ihes dar tantas caças. No momento em que tinham sequer a ameaça de uma pequena queda no mato, eles paravam de caçar regularmente para evitar ter de se casar com ela. Mas esse não é o caso de Kinimnok. Ele é, há muito tempo, um caçador de êxito extraordinário e proclama abertamente que deve seu sucesso a seu casamento com a Mulher Marsupial. É comum vê-lo publicamente 
Sociologias, Porto Alegre, ano 17, no 39, mai/ago 2015, p. 164-196

agarrando o peito e anunciando que a Mulher Marsupial está tentando matá-lo, mas não fez qualquer esforço para romper seu relacionamento com ela parando de caçar. Além disso, ele nunca deixou de caçar frente às dificuldades no cultivo que seu comprometimento exagerado com a mata trouxe a ele e à sua família.

Uma vez, durante meu trabalho de campo, a situação de Kinimnok ficou tão complicada em relação aos alimentos de cultivo que ele foi obrigado a comprar uma horta de taro madura de outra pessoa da comunidade, um tipo de aquisição que os Urapmin consideram muito vergonhosa. Com sua obsessão pela caça, sua aceitação do seu casamento com a Mulher Marsupial e seu fracasso em atender as demandas de tarefas quotidianas de subsistência, Kinimnok é o modelo vivo da intencionalidade desenfreada.

E só estamos falando da caça. A tendência intencional de Kinimnok também é comprovada por sua vida conjugal, pois seu casamento com a NukWanang não é sua única união irregular. Em uma época em que o cristianismo questiona a poligamia, e em que poucos homens a experimentam e ainda menos têm sucesso, Kinimnok manteve por muitos anos múltiplos casamentos com um conjunto de mulheres que está sempre mudando. Seu atual arranjo conubial é particularmente chocante para a sensibilidade Urapmin. Os Urapmins fazem todo o possível para apagar quaisquer distinções entre filhos genéticos, enteados e adotados, e crescer com uma família que, por qualquer razão, confere direitos de nascimento. Portanto, quando Kinimnok casou com a mulher que é atualmente sua esposa primeira e ela trouxe consigo sua filha muito jovem, Kinimnok a criou como se fosse sua. Mas, quando ela atingiu a puberdade, ele se casou com ela. Agora ele é casado com ela e com sua mãe. Os Urapmin reconhecem esse arranjo como perturbadoramente próximo do incesto entre pai e filha e, na melhor das hipóteses, uma ação muito intencional da parte de Kinimnok em relação a sua mulher mais velha. 
Sociologias, Porto Alegre, ano 17, no 39, mai/ago 2015, p. 164-196

A personalidade de Kinimnok, em geral, também é marcada por uma demonstração frequente de obstinação nas interações interpessoais. É especialmente marcante a forma como Kinimnok se enfurece rapidamente e parte para ameaças de violência física, algo que outros Urapmins raramente fazem. Parte da truculência de Kinimnok provém de sua crença de que outros homens estão sempre tentando seduzir suas mulheres. Ela também é alimentada por sua (muito infundada, ao que sei) preocupação de que os outros o estejam difamando pelas costas ou ameaçando enfrentá-lo. Seu medo de invasões é tão exacerbado, e seu pavio curto tão fácil de acender, que ele sequer pode viver em uma aldeia Urapmin normal. Em vez disso, vive em uma propriedade rural própria, a pequena distância de uma aldeia onde vivem seus aliados mais próximos, mantendo uma distância segura de outros que possam incitar seu ciúme e raiva obstinados.

Contudo, há uma forte ironia na situação residencial de Kinimnok, e ela nos direciona para seu status como exemplo do valor da intencionalidade em sua forma mais plenamente realizada. Essa ironia provém do fato de que, embora ele resida fora da aldeia mais próxima de sua casa, Kinimnok é a pessoa que os moradores da aldeia elegeram para servir como "conselheiro distrital" (Komiti) na estrutura de governo formal que foi posta em prática na Urapmin contemporânea. Em seu papel, ele os representa frente à figura líder do governo estatal na comunidade - o Conselheiro - e atua como um mediador de primeira instância em disputas.

Conforme demonstra seu status como conselheiro, o fato de a maioria dos Urapmins achar o comportamento de Kinimnok um exemplo de obstinação não os impede de desenvolver sentimentos positivos a seu respeito. De fato, a maioria dos Urapmins sente alguma afetividade, e até mesmo admiração, por Kinimnok, algo que inicialmente me chocou bastante, uma vez que inicialmente o via como um brutamontes e um bu- 
Sociologias, Porto Alegre, ano 17, no 39, mai/ago 2015, p. 164-196

fão. Em certa ocasião, quando sua raiva chegou a um extremo, e quando muitas pessoas o ouviram ameaçar matar um homem importante de Urapmin, falou-se em levá-lo à Corte Distrital na sede do governo, cerca de seis horas a pé ao leste de Urapmin. A população estava convencida de que o magistrado da corte distrital prenderia Kinimnok por muito tempo por seu comportamento ameaçador. Quando o receio de que Kinimnok estaria destinado a anos de reclusão afastado da comunidade se espaIhou, comecei a ouvir pessoas falando de como sentiriam sua falta. Ele é tão engraçado, ele nos faz rir, diziam. E apontavam que grande caçador ele era, e como sempre era generoso com a comida quando visitavam a casa dele. Perguntei-me, à época, se estaria apenas observando o clima positivo de homenagem que se emociona a antecipação de uma morte iminente (ainda que, nesse caso, uma morte social). Então, muito depois de passado o evento, sem que Kinimnok fosse preso, ocasionalmente testei os sentimentos da população a respeito dele e acabei descobrindo que, de fato, eles eram, intimamente, muito positivos, embora publicamente, por vezes, condenassem seu comportamento. Uma vez perguntei a um jovem quem era sua pessoa favorita em Urapmin. "Kinimnok", ele respondeu sem hesitar. Ele é engraçado, um ótimo contador de histórias, um caçador habilidoso e generoso. Como era o caso de Semis e sua incorporação de um ideal de legalidade vivido sem ceder às demandas da intencionalidade, também ocorria com Kinimnok e sua intencionalidade destemperada: ninguém mais era capaz de viver como ele. Mas com frequência falavam dele, e em muitos aspectos o amavam da maneira como Scheler diz que os exemplares devem ser amados. Através dele, aprenderam por observação como é o valor da intencionalidade quando se realiza plenamente.

Até aqui, identifiquei onde os valores da intencionalidade e da legalidade existem de forma consumada no cenário da vida social Urapmin. 
Sociologias, Porto Alegre, ano 17, no 39, mai/ago 2015, p. 164-196

É através de figuras exemplares como Semis e Kinimnok que os Urapmins encontram esses valores e aprendem a pensar sobre suas próprias vidas nesses termos. Mas e quanto ao valor preeminente do relacionalismo, o valor em benefício do qual as pessoas geralmente equilibram sua realização da legalidade e da intencionalidade? Onde as pessoas encontram esse valor? Elas o encontram, eu sugeriria, em seus homens importantes.

Já escrevi outras vezes sobre os homens importantes de Urapmin de forma bem compatível com a presente argumentação, portanto vou descrevê-los muito rapidamente. Há quatro homens importantes em Urapmin. Não há discordância em relação a quem se qualifica para esse papel e nenhuma sugestão de que alguém mais, exceto esses quatro homens importantes, mereça esse status. A população fala sobre os homens importantes, e sonha com eles, o tempo todo. As pessoas muitas vezes se frustram com seus próprios homens importantes, aqueles a quem seguem pessoalmente, que podem ser bastante prepotentes, e admitem que, em se tratando da lei, eles são muitas vezes homens "maus". Mas, ao mesmo tempo, também reconhecem que os homens importantes, que usam sua vontade para construir aldeias, convencem as pessoas a trabalhar juntas e defendem os direitos de seus seguidores de violações pelos seguidores de outros, também as tratam muitas vezes de maneira recíproca, que demonstra seu respeito pela lei. Ao equilibrar a intencionalidade e a legalidade da forma mais relacionalmente produtiva possível, os homens importantes criam os contextos sociais que permitem a seus seguidores viver produtivamente suas próprias vidas relacionais como um meio-termo entre os dois valores. É por isso que boa parte do dá sentido de segurança à população, a noção de que podem viver suas próprias vidas produtivamente, está associada a seus vínculos com seus homens importantes, de tal forma que frequentemente expressam uma inquietude acentuada quando o homem importante que vive mais próximo deixa a comunidade por um período estendido para visitar amigos ou parentes de fora.

http://dx.doi.org/10.1590/15174522-017003905 
Sociologias, Porto Alegre, ano 17, no 39, mai/ago 2015, p. 164-196

Não pretendo me estender aqui sobre os homens importantes, exceto para observar que, inicialmente, sua existência em Urapmin me deixava confuso. Muitos dos grupos culturalmente semelhantes situados perto de Urapmin não apresentam homens importantes proeminentes como parte de sua organização social. Em termos de relações de produção e troca, os arranjos sociais dos Urapmins, assim como os de seus vizinhos, assumem uma forma geralmente percebida como produzindo homens influentes com estilos diversificados de liderança, em vez do estilo mais concentrado e multifuncional dos homens importantes de Urapmin. Isso posto, fico inclinado a afirmar, e já o fiz mais elaboradamente em outros escritos, que os Urapmins investem tanto em seus homens importantes, e lhes dão tanta autoridade, não porque precisem deles para operar suas vidas sociais de forma pragmática, mas sim por necessitarem deles como exemplos que demonstrem como o valor do relacionalismo pode ser consumado numa síntese de realizações parciais dos valores da legalidade e da intencionalidade, que Semis e Kinimnok representam tão completamente. É encontrando e refletindo sobre exemplares dos três valores do relacionalismo, legalidade e intencionalidade que os Urapmin identificam as cordas inter-humanas pelas quais podem se erguer em suas vidas sociais, e nesse cenário os homens importantes, que exemplificam a realização do valor preeminente do relacionalismo, fornecem as cordas mais resistentes.

Tendo, até aqui, discutido em certo nível de detalhe como as pessoas encontram valores plenamente expressos na forma de indivíduos exemplares, gostaria de brevemente apontar como essa análise pode ser ampliada demonstrando que elas também podem vivenciá-los através da participação em instituições, e especialmente pela participação em alguns rituais. Que os rituais, pelo menos algumas vezes, representam uma imagem idealizada do mundo não é uma percepção nova. Jonathan $Z$. Smith (1982, p. 63), há muito tempo, definiu o ritual como um meio de 
encenar como as coisas deveriam ser em tensão consciente com a forma como as coisas são, de tal maneira que essa perfeição ritualizada seja lembrada durante o curso ordinário e não controlado das coisas. Kapferer (2006, p. 673), mais recentemente, defendeu uma perspectiva do ritual como constituinte de um espaço de virtualidade que "permite libertar-se das restrições ou determinações da vida quotidiana" não para deixar esta última e suas preocupações para trás, mas sim para desacelerar seu fluxo e velocidade (p. 676) de modo a poder avaliá-la e, talvez, transformar seus elementos. Acompanhando as análises de Kapferer e Smith, quero argumentar que alguns rituais realizam esse processo de desaceleração da produção e aperfeiçoamento da forma das representações precisamente por valores. Ou seja, eles permitem às pessoas suspender a relação complexa entre valores e ações que perdura na vida quotidiana - na qual se faz essencialmente apenas um pequeno progresso em meio a extremadas tentativas de realizar cadeias de transformação de valor, ou se age de maneira a realizar alguns valores, mas apenas de forma limitada -, e em vez disso vivenciar o que seria realizar um valor plenamente. Tal valor é consumado em um espaço que foi, de certa forma, simplificado, mas sua realização ritualística ainda assim também permanece em jogo no fluxo corrido da vida quotidiana, pois cada ritual oferece uma amostra da exemplaridade que vai, a partir de então, exigir um pouco da energia de cada participante no ritual em favor de continuar a realização do valor envolvido em contextos de ação mais quotidianos.

Para ilustrar essa abordagem da análise do ritual como algo que propicia a vivência de um valor plenamente realizado, discutirei brevemente o ritual cristão Urapmin da dança do Espírito, ou o que eles chamam de "discoteca do Espírito". Para entender o trabalho que a dança do Espírito faz para imitar um valor plenamente realizado, é preciso saber que o cristianismo Urapmin desconsidera em grande parte o valor tradicional 
Sociologias, Porto Alegre, ano 17, no 39, mai/ago 2015, p. 164-196

Urapmin do relacionalismo em favor de sua própria promoção do valor do individualismo. Em se tratando do seu cristianismo, os Urapmins reconhecem que precisam se salvar como indivíduos e que, em sua busca por essa salvação, suas relações não os ajudarão. Como me disse um homem, minha mulher não pode tirar parte da sua fé e dá-la para mim. No que diz respeito à fé, todo mundo tem que ter a sua própria. E a forma como a fé é demonstrada é através de um comprometimento constante com a legalidade, pois é a intenção que leva ao pecado. É por isso que o cristianismo Urapmin só reconhece o valor da legalidade e não promove a intencionalidade em qualquer situação, mesmo quando ela contribui com a realização de objetivos relacionais. É porque Semis, a quem conhecemos anteriormente, vive sob esse código cristão que ele corresponde para os Urapmins a um exemplar de comportamento conforme a lei.

As pessoas conseguem reconhecer a forma da legalidade inflexível ao observar Semis. Mas elas também conseguem vivenciá-la por sua conta através da dança do Espírito, um cenário em que a legalidade também ajuda a realizar o valor preeminente cristão do individualismo na forma mais plena que ele pode ter na vida Urapmin. As danças do Espírito são danças circulares feitas à noite dentro da igreja. Durante a dança, alguns dos participantes são possuídos pelo Espírito Santo. Uma vez que isso aconteça, eles começam a se debater desenfreadamente e são "controlados" por outros participantes, que os seguram e fazem o melhor possível para evitar que machuquem a si mesmos ou a outros. Durante uma dança bem sucedida, diversas pessoas são possuídas assim, por cerca de uma hora. No ápice do rito, o cenário dentro da igreja pode ser caótico, com todos os possuídos cambaleando erraticamente pelo salão enquanto os outros se esforçam para manter o padrão circular da dança. Depois de algum tempo, o Espírito sairá dos dançarinos possuídos, um por um. Quando o Espírito sai de uma pessoa, ela cai no chão, completamente 
Sociologias, Porto Alegre, ano 17, no 39, mai/ago 2015, p. 164-196

amolecida, efetivamente inconsciente e, como dizem os Urapmins, em paz. Após a possessão, essas pessoas ficam deitadas no chão da igreja nesse estado durante algum tempo, enquanto os dançarinos reduzem o passo e, por fim, param. Os participantes permanecem na igreja até que os que haviam sido possuídos estejam novamente conscientes. Então, todos rezam juntos e o ritual acaba.

No entendimento dos Urapmins, a violência da possessão durante a dança do Espírito se deve à batalha dentro do coração da pessoa possuída entre o Espírito Santo e seus pecados. Vale observar também que isso leva a um comportamento excepcionalmente intencional, uma vez que os dançarinos sacodem-se violentamente sem consideração pelos que estão ao seu redor. A conclusão da possessão ocorre quando o Espírito finalmente consegue "expulsar" os pecados do corpo da pessoa e ela é então deixada num estado de paz e "tranquilidade". Antes de começar a dança do Espírito, todos devem confessar seus pecados para um pastor ou diácono, que rezará por eles e dirá a Deus que os pecados Lhe foram dados. Mas é somente durante a possessão da dança do Espírito que os pecados são finalmente levados do corpo. Isso deixa a pessoa pronta para a salvação. Para os Urapmins, a pessoa antes possuída, deitada imóvel e sozinha no chão da igreja, representa a plena realização de uma pessoa seguidora da lei, seus corpos frouxos imperturbados por aspirações intencionais. Quem está em estado pós-possessão, deitado no chão da igreja sozinho e desatendido, também representa a realização mais plena possível do indivíduo salvo antes do retorno de Jesus. Uma vez que, como alguém consolidou o entendimento geral dos Urapmins para mim, tão logo as pessoas saem da igreja elas começam a pecar novamente, é apenas nesse momento, no final do rito, que se pode ter a certeza da salvação de si ou de outros. E é, portanto, o único momento na vida social Urapmin que o valor de tornar-se um indivíduo completamente seguidor da lei e digno

http://dx.doi.org/10.1590/15174522-017003905 
Sociologias, Porto Alegre, ano 17, no 39, mai/ago 2015, p. 164-196

da salvação é plenamente visível. A dança do Espírito fornece, assim, uma imagem exemplar do valor do individualismo cristão Urapmin exercido em sua forma mais plena.

\section{Conclusão}

Tendo considerado a questão da exemplaridade e a existência de valores por diversos ângulos etnográficos, quero voltar-me a uma breve conclusão de Louis Dumont, que pode ser considerado o mais importante antropólogo teórico dos valores, escreveu que:

Se nos prendermos não mais à função, mas ao significado, então é preciso compreender cada tipo de representação ali onde ela está plenamente sublinhada e elaborada, ali onde ela se eleva à predominância, e não lá onde ela é mantida em um estado rudimentar ou residual (DUMONT, 1980, p. xxxix).

Quem "compreende", no comentário de Dumont, é evidentemente o analista. Mas já argumentei aqui que as pessoas que estudamos também precisam compreender as representações - pelo menos as representações de valores - onde elas estão "plenamente sublinhas e elaboradas". É pela compreensão de tais representações plenamente elaboradas que as pessoas vivenciam a existência dos valores. Que os valores começam a existir dessa forma foi a substância da minha argumentação.

Para essa argumentação, foi essencial a afirmação de que as pessoas encontram versões plenamente elaboradas de valores não tanto por receberem definições culturais abstratas deles, mas sim tendo contato com pessoas e instituições que os exemplifiquem. A vida quotidiana, para quase todas as pessoas, não é de fato marcada pela realização de valores fundamentais, mas pela execução de ações voltadas ao alcance de valores de muito menor nível ou à realização de alguns valores de forma negociada. É por isso que pessoas e instituições exemplares são tão im- 
Sociologias, Porto Alegre, ano 17, no 39, mai/ago 2015, p. 164-196

portantes na vida em sociedade: elas nos oferecem valores de uma forma que nossas experiências do dia-a-dia raramente conseguem. Finalizando, eu gostaria de ir mais a fundo e sugerir que são nossos encontros com valores fundamentais incorporados por pessoas e instituições exemplares que emprestam às nossas vidas um senso de propósito moral e de investimento no futuro, a qualidade progressista de andar em direção ao bem, tão fundamental para que sigamos em frente. Quando tais pessoas e instituições exemplares são difíceis de encontrar em nosso meio social, o investimento moral no futuro possivelmente vacilará. Mas essa é uma discussão sobre o que os valores fazem, não sobre onde no mundo eles estão, e, portanto a deixarei para outro momento.

Resta, portanto, encerrar o que referenciei no início como um dos principais marcos que envolvem minha argumentação - aquele relacionado ao nosso atual momento anticultural e a como podemos resgatar de sua crítica contundente alguns dos dados essenciais da análise cultural que não queremos perder. Tendo definido os valores como um desses dados aos quais vale aferrar-nos, tentei descrever como as pessoas podem ver-se ligadas a valores não porque esses thes tenham sido legados de cima, por uma duradoura cultura compartilhada, mas porque às vezes elas os encontram na forma de exemplos reais. Tais exemplos, quando encontrados, exibem uma força que ajuda as pessoas a pensar sobre aquilo que elas realmente buscam ao longo de suas vidas que não pareça estar direcionado para muito além de objetivos imediatos. Se eu tive êxito em minha argumentação, espero ter conseguido transmitir que é possível pensar sobre esse aspecto direcionado a valores, moralmente informado e progressista da vida humana, sem depender das noções mais antigas de cultura, ainda que não queira descartar a possibilidade de voltar a essas noções em outro momento. 
Sociologias, Porto Alegre, ano 17, no 39, mai/ago 2015, p. 164-196

Joel Robbins - Atuou durante vários anos como professor na Universidade da Califórnia, San Diego e como professor visitante em diversas universidades. Atualmente é professor de Antropologia Social na cátedra Sigris Rausing da Universidade de Cambridge. $\gg$ jr626@cam.ac.uk

\section{Referências}

1. ALBROW, Martin. Max Weber's Construction of Social Theory. New York: St. Martin's Press, 1990.

2. DUMONT, Louis. Homo Hierarchicus: The Caste System and its Implications. M. Sainsbury, L. Dumont, and B. Gulati (transl.). Chicago: University of Chicago Press, 1980.

3. DURKHEIM, Émile. Sociology and Philosophy. D. F. Pocock (transl.). New York: Free Press, 1974.

4. FERRARA, Alessandro. The Force of the Example: Explorations in the Paradigm of Judgement. New York: Columbia University Press, 2008.

5. KAPFERER, Bruce. Virtuality. In: KREINATH, J.; SNOEK, J.; STAUSBERG, M. (eds.). Theorizing Rituals: Classical Topics, Theoretical Approaches, Analytical Concepts. Leiden: Brill, 2006. P. 671-684.

6. LAIDLAW, James. The Subject of Virtue: An Anthropology of Ethics and Freedom. Cambridge: Cambridge University Press, 2013.

7. MUNN, Nancy M.. The Fame of Gawa: A Symbolic Study of Value Transformation in a Massim (Papua New Guinea) Society. New York: Cambridge University Press, 1986.

8. ROBBINS, Joel. Becoming Sinners: Christianity and Moral Torment in a Papua New Guinea Society. Berkeley: University of California Press, 2004.

9. ROBBINS, Joel. On Becoming Ethical Subjects: Freedom, Constraint, and the Anthropology of Morality. Anthropology of This Century, 2012a.

10. ROBBINS, Joel. Cultural Values. In: FASIN, D. (ed.) A Companion to Moral Anthropology. Malden, MA: Wiley-Blackwell, 2012b. P. 117-132.

11. ROBBINS, Joel. Monism, Pluralism and the Structure of Value Relations: A Dumontian Contribution to the Contemporary Study of Value. Hau: Journal of Ethnographic Theory 3(1), 2013, p. 99-115.

12. SCHELER, Max. Formalism in Ethics and a Non-Formal Ethics of Values: A New Attepmt toward the Foundation of an Ethical Personalism. Evanston: Northwestern University Press, 1973. 
Sociologias, Porto Alegre, ano 17, no 39, mai/ago 2015, p. 164-196

13. SCHELER, Max. Person and Self-Value: Three Essays. M. S. Frings (transl.). Dordrecht: MartinusNijhoff, 1987.

14. SCHNÄDELBACH, Herbert. Philosophy in Germany 1831-1933. Cambridge: Cambridge University Press, 1984.

15. SMITH, Jonathan Z. Imagining Religion: From Babylon to Jonestown. Chicago: University of Chicago Press, 1982.

Recebido em: 10/09/2014

Aceite Final: 11/12/2014

http://dx.doi.org/10.1590/15174522-017003905 